\title{
Neuron-specific Mafb knockout causes growth retardation accompanied by an impaired growth hormone/insulin-like growth factor I axis
}

\author{
Shayida MAIMAITI ${ }^{1,5)}$, Ryusuke KOSHIDA ${ }^{2)}$, Masami OJIMA ${ }^{1)}$, Kaushalya KULATHUNGA ${ }^{1,3)}$, \\ Hisashi OISHI ${ }^{4)}$ and Satoru TAKAHASHI ${ }^{1)}$ \\ 1)Department of Anatomy and Embryology, University of Tsukuba, 1-1-1 Tennodai, Tsukuba, Ibaraki 305-8575, \\ Japan \\ ${ }^{2)}$ Department of Anatomy and Neuroscience, University of Tsukuba, 1-1-1 Tennodai, Tsukuba, Ibaraki 305-8577, \\ Japan \\ 3) Ph.D. Program in Human Biology, School of Integrative and Global Majors, University of Tsukuba, 1-1-1 \\ Tennodai, Tsukuba, Ibaraki 305-8577, Japan \\ ${ }^{4)}$ Department of Comparative and Experimental Medicine, Nagoya City University, 1 Kawasumi, Mizuho-cho, \\ Mizuho-ku, Nagoya, Aichi 467-8601, Japan \\ 5) Present address: Okinawa Institute of Science and Technology Graduate University, 1919-1 Tancha, Onna-son, \\ Okinawa 904-0412, Japan
}

\begin{abstract}
Mammalian postnatal growth is regulated primarily by the growth hormone (GH)/insulin-like growth factor I (IGF-I) axis. MafB is a basic leucine zipper (bZip) transcription factor that has pleiotropic functions. Although MafB plays a critical role in fetal brain development, such as in guidance for hindbrain segmentation, its postnatal role in neurons remains to be elucidated. To investigate this, we used neuron-specific Mafb conditional knockout (cKO) mice. In addition to an approximately 50\% neonatal viability, the Mafb cKO mice exhibited growth retardation without apparent signs of low energy intake. Notably, serum IGF-I levels of these mice in the postnatal stage were lower than those of control mice. They seemed to have a neuroendocrine dysregulation, as shown by the upregulation of serum GH levels in the resting state and an inconsistent secretory response of GH upon administration of growth hormone-releasing hormone. These findings reveal that neuronal MafB plays an important role in postnatal development regulated by the GH/IGF-I axis.
\end{abstract}

Key words: growth hormone, growth retardation, insulin-like growth factor I, MafB, nutritional status

\section{Introduction}

Mammalian postnatal growth is regulated primarily by the growth hormone $(\mathrm{GH})$ /insulin-like growth factor I (IGF-I) axis [20]. GH is secreted from somatotrophic cells in the anterior pituitary glands in a pulsatile manner regulated by hypothalamic growth hormone-releasing hormone (GHRH). In addition, GH secretion is enhanced by ghrelin and inhibited by somatostatin. GH induces hepatic IGF-I secretion that plays a crucial role in promoting linear skeletal growth during childhood [31]. In addition to regulation by GH, circulating IGF-I is affected by nutritional status, namely, low energy intake or protein deficiency that can suppress hepatic IGF-I

(Received 13 December 2018 / Accepted 5 April 2019 / Published online in J-STAGE 16 May 2019)

Corresponding authors: R. Koshida.e-mail: rkoshida-myz@umin.ac.jp

S. Takahashi.e-mail: satoruta@md.tsukuba.ac.jp

(c) $\$($ This is an open-access article distributed under the terms of the Creative Commons Attribution Non-Commercial No Derivatives (by-nc-nd) License <http://creativecommons.org/licenses/by-nc-nd/4.0/>. 
secretion $[6,12]$. Additionally, proteolytic enzymes attack certain conformations of circulating IGF-I, as evidenced by the lower half-life (a few minutes) of free IGF-I versus the stabilized complex (more than $10 \mathrm{~h}$ ) that contains IGF binding protein 3 (IGFBP3) [1] and the acid-labile subunit (ALS) [29].

MafB is a basic leucine zipper (bZip) transcription factor that belongs to the large Maf family, whose proteins commonly bind to a consensus DNA sequence referred to as the Maf recognition element (MARE) [5]. MafB plays a crucial role in fetal development of several organs such as the kidneys [21], inner ear [4], pancreatic islets [8], and parathyroid glands [15]. MafB also plays a role in maintenance of adult tissues through transcription of key molecules such as glucagon [16], parathyroid hormone [23], nephrin, and podocin [22, 27].

MafB is diffusely expressed in the developing brain $[3,19]$. Earlier studies using Kreisler mice carrying Mafb mutations have revealed that it guides hindbrain segmentation in the early embryonic stage [4]. MafB is also essential for development of the pre-Bötzinger complex in the medulla oblongata, which is responsible for respiratory rhythmogenesis [2]. However, the postnatal role of MafB in neurons remains to be elucidated.

Here, we have generated neuron-specific Mafb conditional knockout (cKO) mice. Approximately half of the Mafb cKO mice died within $48 \mathrm{~h}$ after birth, and the survivors exhibited growth retardation. There was no evidence of low energy intake in these mice, but GH/ IGF-I axis impairment was observed. Our study reveals that the function of MafB in neurons is important for postnatal growth regulated by the GH/IGF-I axis.

\section{Materials and Methods}

Mice

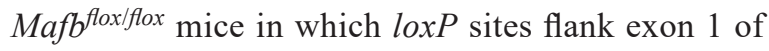
the $M a f b$ gene [28], $M a f b$-deficient $\left(\mathrm{Mafb}^{-/-}\right)$mice in which the GFP gene is knocked-in in the Mafb locus [21], and R26GRR mice in which a switch of constitutive expression from GFP to tdsRed is induced by Cre-mediated recombination in the ROSA locus [11] were described previously. Nes-Cre mice, neuron-specific Cre driver mice [13], were kindly provided from by R. Kageyama (Kyoto University). All mice were maintained on the $\mathrm{C} 57 \mathrm{BL} / 6 \mathrm{~J}$ background. The pups were weaned at 3 weeks of age. All experiments were performed accord- ing to the Guide for the Care and Use of Laboratory Animals at the University of Tsukuba.

\section{Brain sections and immunohistochemistry}

Mice at embryonic day 12.5 (E12.5) and postnatal day 0 (P0) were fixed with paraformaldehyde (PFA) in PBS at $4{ }^{\circ} \mathrm{C}$ overnight. Next, whole embryos and brains at $\mathrm{P} 0$ were cryoprotected in 30\% sucrose and embedded in Tissue-Tek OCT compound (Sakura Finetek, Tokyo, Japan). Frozen sections were prepared at a thickness of $20 \mu \mathrm{m}$ using a cryostat. For immunohistochemistry, sections were blocked with $10 \%$ normal goat serum plus $0.3 \%$ Triton X-100 in PBS for $1 \mathrm{~h}$ at room temperature. The sections were incubated with anti-MafB antibody (1:500, IHC-00351, Bethyl Laboratories, Montgomery, TX, USA) overnight at $4^{\circ} \mathrm{C}$. After washing, slides were incubated with Alexa Fluor 594-conjugated secondary antibody (Molecular Probes, Eugene, OR, USA) for $1 \mathrm{~h}$ at room temperature. Fluorescent images were acquired using a Biorevo BZ-9000 fluorescence microscope (Keyence, Osaka, Japan). For assessment of efficiency of Cre-mediated recombination, 4 sections were prepared from each sample, and tdsRed-positive areas were measured with ImageJ software (NIH, Bethesda, MD, USA).

\section{Measurements of blood glucose and serum IGF-I}

Blood was collected by cardiac puncture, and glucose concentration was immediately measured with a Medisafe glucometer (Terumo, Tokyo, Japan). After clotting, blood was centrifuged at $3,000 \mathrm{~g}$ for $10 \mathrm{~min}$, and the resultant supernatant was collected. Serum IGF-I concentration was measured with a Mouse/Rat IGF-I Quantikine ELISA kit (MG100, R\&D systems, Minneapolis, MN, USA).

\section{GHRH administration and GH measurement}

Mice at 4 weeks of age were injected intraperitoneally with $5 \mu \mathrm{g}$ of human GHRH (GHRH-288H, Creative Biomart, Shirley, NY, USA). Blood was repeatedly collected through a facial vein before and 5 min after GHRH administration. To minimize the effect of diurnal variation of $\mathrm{GH}$, the experiments were performed between 9 a.m. and 11 a.m. Serum GH concentration was measured with a Rat/Mouse GH ELISA (EZRHGH-45K, MilliporeSigma, Burlington, MA, USA).

\section{Quantitative RT-PCR}

Total RNA was extracted from snap-frozen livers at 
P14 with Isogen (Nippon Gene, Tokyo, Japan), and cDNA was synthesized with a QuantiTect Reverse Transcription kit (QIAGEN, Hilden, Germany), each according to manufacturers' instructions. Real-time PCR was run on a Thermal Cycler Dice Real Time System Single (Takara, Shiga, Japan) with SYBR Green PCR master mix (Takara). The primer sequences used were as follows: Pck1 forward, 5'-CACCATCACCTCCTGGAAGA-3'; Pck1 reverse, 5'-GGGTGCAGAATCTCGAGTTG-3'; G6pc forward, 5'-CGACTCGCTATCTCCAAGTGA-3'; G6pc reverse, 5'-GTTGAACCAGTCTCCGACCA-3'; $F g f 21$ forward, 5'-GTGTCAAAGCCTCTAGGTTTCTT-3'; Fgf21 reverse, 5'-GGTACACATTGTAACCGTCCTC-3'; Hprt forward, 5'-TTGTTGTTGGATATGCCCTTGACTA-3'; Hprt reverse, 5'-AGGCAGATGGCCACAGGACTA-3'. All PCR was performed duplicates in all cases, and amplification products were quantified by the standard curve method. The mRNA levels of each gene were normalized to Hprt.

\section{Statistical analysis}

Data are expressed as means \pm SEMs. Differences between the two groups were analyzed using a Student $t$-test or a Wilcoxon rank-sum test. For intraindividual comparison, a paired $t$-test was applied. For comparison of survival rate, a Fisher exact test was applied. For multiple comparisons, a Tukey honest significant differences (HSD) test or a Bonferroni correction was applied. All statistical analyses were performed with R software (http://www.r-project.org). Probability values of less than 0.05 were considered significant.

\section{Results}

Neuron-specific deletion of the Mafb gene causes neonatal death

To delete the Mafb gene specifically in the neural lineage using a Cre-loxP strategy, we chose a line of NesCre mice [13]. Given that spatiotemporal validity of Nes-Cre mice has been argued [14, 17], we initially evaluated the recombination efficiency of the Nes-Cre mice by crossing with GRR26R mice, reporter mice in which cells are labeled with tdsRed by Cre-mediated recombination [11] (Nes-Cre;R26GRR mice). We found that recombination-induced tdsRed expression is incomplete in the brains at E12.5, particularly in the cerebral cortex and tectum of the midbrain (Fig. 1A). At P0, tdsRed-positive areas covered more than $90 \%$ of the brain parenchyma of the Nes-Cre;R26GRR mice (Fig. 1B, D). We also analyzed MafB expression using $\mathrm{Mafb}^{\mathrm{GFP} /+}$ mice [21] and confirmed that MafB is already expressed in the hindbrain at E12.5 (Fig. 1C). These results imply that residual activity of MafB in embryonic neurons may have some effects on the phenotype of the Mafb cKO mice.

Next, we generated neuron-specific Mafb cKO mice by crossing the Nes-Cre mice with Mafb flox/flox mice [28] (Nes-Cre;Mafb floxfflox mice). Furthermore, we performed immunohistochemistry for MafB using Nes$\mathrm{Cre} ; M a f b^{f l o x} / G F P$ mice and confirmed successful deletion of MafB protein in GFP-positive ("MafB-positive") cortical neurons at $\mathrm{P} 0$ (Fig. 1E).

Whole-body deletion of the Mafb gene leads to $100 \%$ neonatal death due to respiratory arrest associated with abnormalities in fetal brain development [2]. Within 48 h after birth, $48 \%$ (12 out of 25) of the Mafb cKO mice pups died, which is far higher compared with the $4 \%$ (1 out of 26) of the Mafb flox/flox pups (Fig. 1F). This result reinforces the idea that MafB plays an important role in neural development that facilitates perinatal survival.

\section{Neuron-specific Mafb cKO mice exhibit growth retardation}

We monitored postnatal growth of the surviving Mafb cKO mice. On the day of birth, no significant difference in body weight was observed between the $M a f b \mathrm{cKO}$ and two control (Nes-Cre;Mafb $b^{f l o x /+}$ and Mafb $b^{f l o x / f l o x}$ ) mice (Fig. 2A). At the postnatal stage, however, weight gain in $M a f b$ cKO mice was stunted compared with the control mice (Figs. 2A and B). After weaning, the Mafb cKO mice started to catch up with the control mice (Fig. 2C), resulting in a marginal difference in body weight among genotypes at 12 weeks of age (Fig. 2D).

Neuron-specific Mafb cKO mice exhibit no signs of low energy intake in the postnatal stage

Since low energy intake as a result of poor suckling could be a cause of growth retardation, we investigated the nutritional status of Nes-Cre;Mafb fox/flox mice. Blood glucose levels in the Mafb cKO mice were comparable to those of Mafb floxfflox mice (Fig. 3A). To further test the possibility that activated gluconeogenesis compensates for low energy intake [18], we examined expression levels of gluconeogenesis-related genes ( $P c k 1, G 6 p c$, and $F g f 21)$ in the liver. The qRT-PCR experiments did not show any significant differences in these genes. (Fig. 

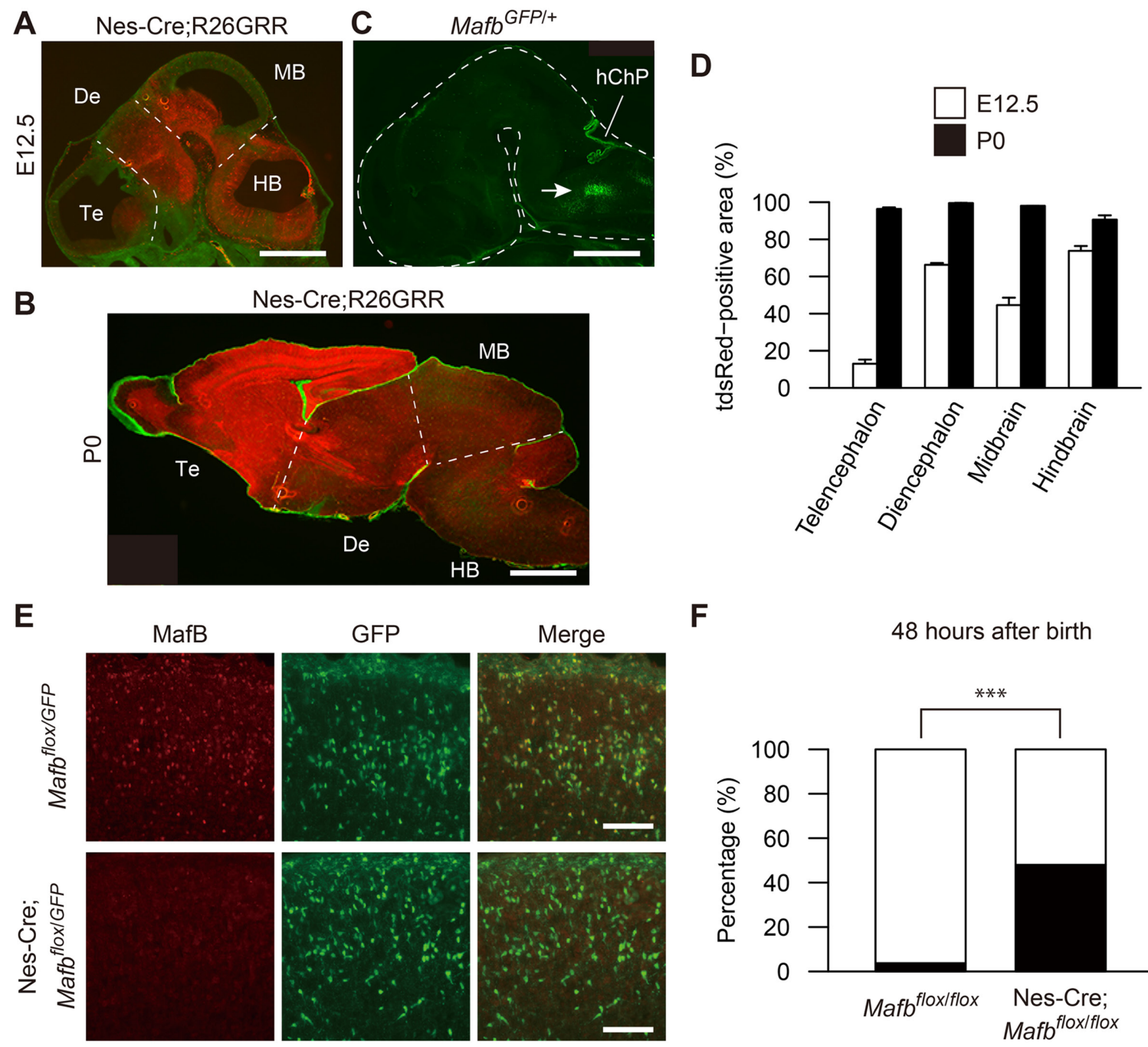

$\mathbf{F}$

48 hours after birth

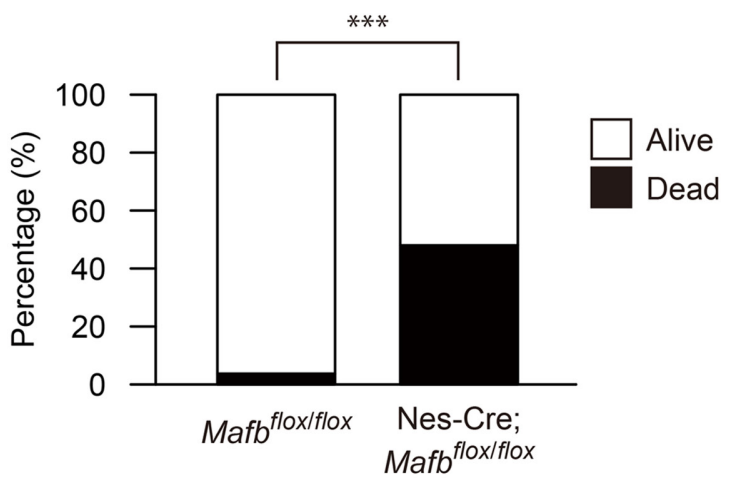

Fig. 1. Neuron-specific deletion of $M a f b$ gene causes neonatal death. Parasagittal images of the Nes-Cre;R26GRR brains at E12.5 (A) and P0 (B) and of the Mafb ${ }^{G F P /+}$ brain at E12.5 (C). (A, B) tdsRed (red) and GFP (green) indicate areas with and without Cremediated recombination, respectively. Te, telencephalon; De, diencephalon; MB, midbrain; HB, hindbrain. Scale bars: $1 \mathrm{~mm}$. (C) The GFP signals, which recapitulate endogenous MafB expression, are obviously observed in the hindbrain (arrow) and the hindbrain choroid plexus (hChP). Scale bar: $1 \mathrm{~mm}$. (D) Percentage of tdsRed-positive areas in the different brain regions of the Nes-Cre;R26GRR mice at E12.5 and P0. n=3 per group. (E) Immunohistochemical staining of MafB in the cerebral cortices at P0. MafB immunoreactivity (red) is absent in the "MafB-positive" neurons (green) of Nes-Cre;Mafb ${ }^{\text {flox/GFP }}$ pups (lower panel). Scale bar: $100 \mu \mathrm{m}$. (F) Neonatal outcome at $48 \mathrm{~h}$ after birth. $* * * P<0.001$, Fisher exact test.

3B). According to these results, the Mafb cKO mice exhibited no signs of low energy intake.

The GH/IGF-I axis is impaired in neuron-specific Mafb cKO mice

To identify the cause of growth retardation in the Mafb cKO mice, we measured circulating levels of GH and IGF-I that critically regulate body size [31]. Notably, serum IGF-I levels in the Mafb cKO mice were significantly lower than those in the Mafb flox/flox mice (Fig. 4A).
We further investigated GH secretory capacity from the anterior pituitary gland in response to GHRH administration and found that, in the basal state, serum GH levels in the Mafb cKO mice were significantly higher than those in Mafb $b^{f l o x} / f l o x$ mice. Upon administration of GHRH, Mafb $b^{f l o x} / f t o x$ mice consistently exhibited enhanced GH secretion while the Mafb cKO mice had an inconsistent response to GHRH (Fig. 4B). 
A

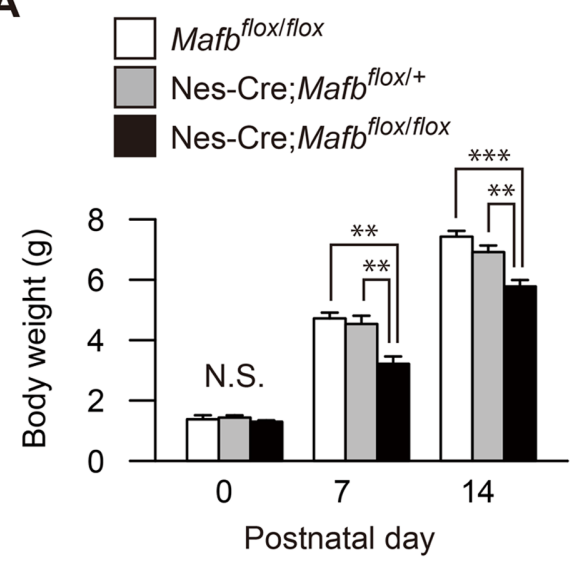

C

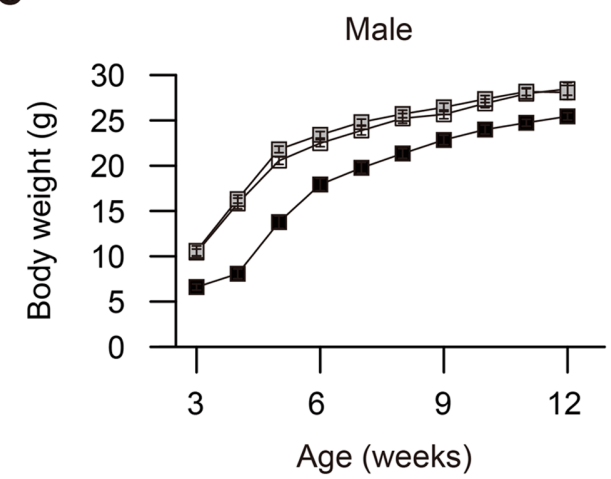

B

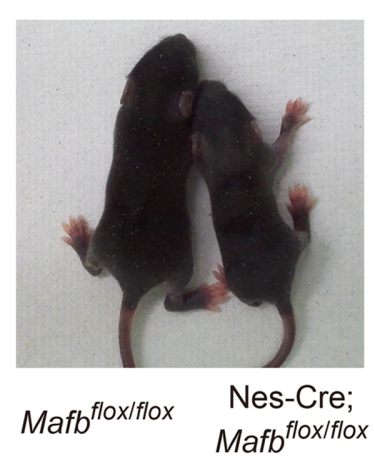

D

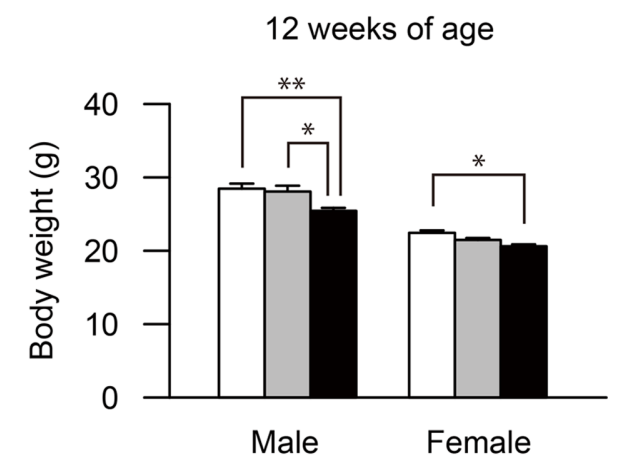

Fig. 2. Neuron-specific $M a f b \mathrm{cKO}$ mice exhibit growth retardation. (A) Body weight during the postnatal stage in each genotype. $\mathrm{n}=5-15$ per group. $* * P<0.01$, Tukey honest significant differences (HSD) test. $* * * P<0.001$, Tukey HSD test. N.S., not significant. (B) P7 pups of Mafb flox/flox (left) and Nes-Cre;Mafb flox/fox (right). (C) Growth curves after weaning of male (left) and female (right) mice. $\mathrm{n}=10-15$ per group. (D) Differences in body weight between genotypes at 12 weeks of age. ${ }^{*} P<0.05$, Tukey HSD test. $* * P<0.01$, Tukey HSD test.

A

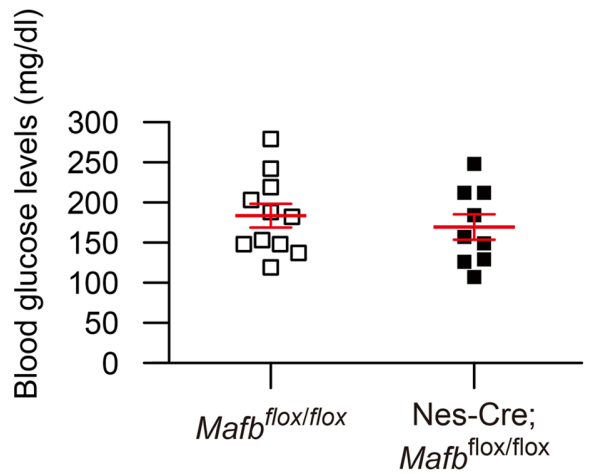

B

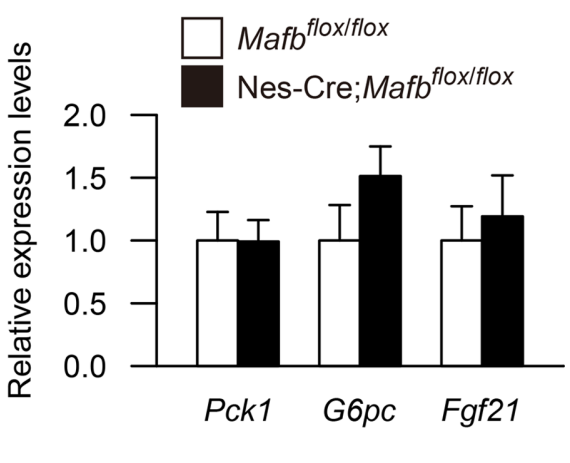

Fig. 3. Neuron-specific Mafb cKO mice exhibit no signs of low energy intake in the postnatal stage. (A) Blood glucose levels at P14. $\mathrm{n}=11$ (Mafb $\left.b^{f l o x} / f \circ x\right)$ and 9 (Nes-Cre; Maff $\left.b^{\text {flox/flox }}\right)$. Red lines represent means \pm SEMs. No significant difference is found between genotypes (Student $t$-test). (B) Quantitative RT-PCR analysis does not show upregulation of gluconeogenesis-related genes ( $P c k 1, G 6 p c$, $F g f 21)$ in the livers of Nes-Cre;Mafb flox/flox mice at P14 (Student $t$-test). $\mathrm{n}=4$ per group. 
A

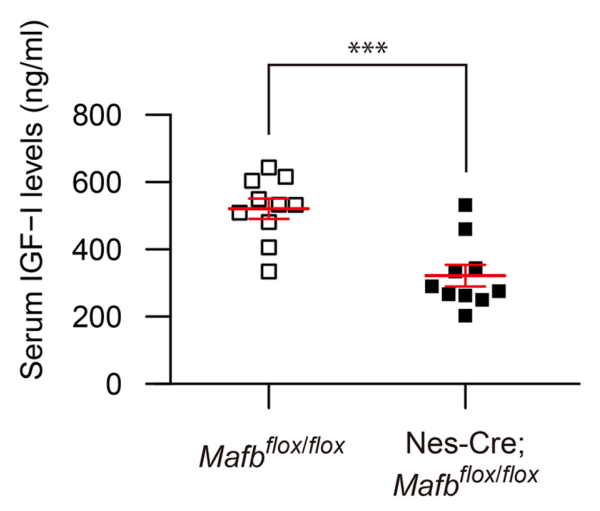

B

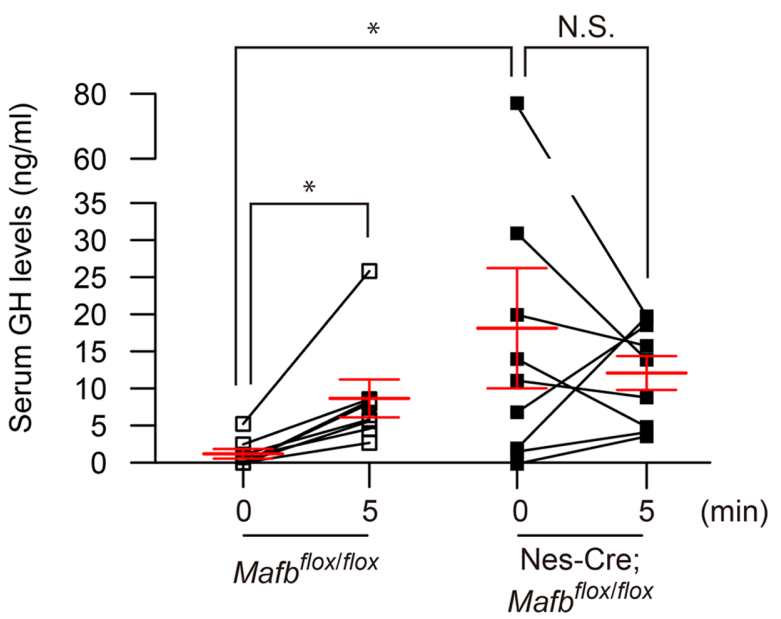

Fig. 4. The growth hormone (GH)/insulin-like growth factor I (IGF-I) axis is impaired in neuron-specific Mafb cKO mice. (A) Serum IGF-I levels at 4 weeks of age. $n=10$ per group. ${ }^{* * *} P<0.001$, Student $t$-test. (B) Serum GH levels before and $5 \mathrm{~min}$ after intraperitoneal administration of growth hormone-releasing hormone (GHRH) $(5$ $\mu \mathrm{g})$ at 4 weeks of age. $\mathrm{n}=8\left(\right.$ Mafb $\left.^{\text {flox } f f l o x}\right)$ and 9 (Nes-Cre;Mafb $\left.b^{\text {flox } f f l o x}\right) . * P<0.05$, paired $t$-test $(0$ min vs. 5 min)

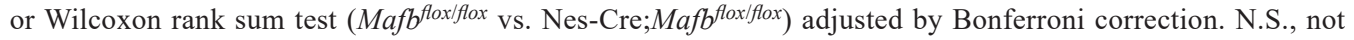
significant. Red lines represent means \pm SEMs.

\section{Discussion}

In the present study, we generated and analyzed neuron-specific Mafb cKO mice. We found that half of these mice die within $48 \mathrm{~h}$ after birth and that the surviving pups exhibit stunted growth. Analysis of blood glucose and gene expression related to gluconeogenesis did not indicate any low energy intake; however, serum IGF-I levels of the Mafb cKO mice were lower than those of control mice. Conversely, we found that serum GH levels (upstream of IGF-I) were upregulated at rest in the Mafb cKO mice but that GHRH-induced GH secretion in these mice was inconsistent. Collectively, our findings reveal that neuronal MafB plays an important role in postnatal development.

Whole-body deletion of Mafb gene causes $100 \%$ neonatal death by respiratory arrest, which may be attributed to abnormal development of the pre-Bötzinger complex in the medulla oblongata [2]. In our study, the neonatal mortality rate of the Mafb cKO pups was approximately $50 \%$. Although we did not examine the respiratory activity of these mice, it is likely that their respiratory rhythmogenesis after birth is impaired due to lack of neuronal MafB. Given the results of our histological analysis using Nes-Cre;R26GRR mice, the reduction of mortality rate may be attributed to incomplete deletion of neuronal MafB in the early embryonic stage. Our results do reinforce the idea that MafB in the developing neurons plays a critical role in preparing neonates for adaptation to the postnatal environment.

Although the surviving Mafb cKO pups exhibit growth retardation, it should be noted that a Nes-Cre transgene per se may cause problems with the growth of transgenic mice. In fact, the Nes-Cre mouse line from the Jackson Laboratory (No. 003771, https://www.jax.org/ strain/003771) has metabolic and endocrine phenotypes including lower production of anterior pituitary hormones such as GH and thyroid stimulating hormone (TSH) [7, 9]. In our study, Nes-Cre; $M a f b^{f o x /+}$ mice were comparable in body weight to Mafb flox/flox mice, and moreover, the $M a f b$ cKO mice were significantly smaller than either of these two mice. Therefore, it is safe to say that this Nes-Cre transgene [13] does not account for the growth retardation of the Mafb cKO mice.

To probe the phenotype of Mafb cKO mice, we analyzed nutritional status, as it is critical for postnatal growth, and abnormal brain development is often accompanied by poor suckling [26]. Although ingested milk amounts are quite difficult to measure, activation of gluconeogenesis can serve as a biomarker for low energy intake [18]. However, gluconeogenesis upregulation was not observed in our study.

Given that the GH/IGF-I axis is critical for postnatal growth [31], reduction of circulating IGF-I is most 
likely a cause of growth retardation in the Mafb cKO mice. We also found that basal GH levels are elevated in the Mafb cKO mice, which is probably due to attenuated negative feedback from IGF-I to somatotrophic cells in the pituitary [6]. In addition to indirect effects via IGF-I, GH has a direct effect on promoting longitudinal skeletal growth independently of IGF-I [30]. Thus, upregulation of basal GH levels may contribute to the growth of the Mafb cKO mice catching up after weaning. Furthermore, inconsistent GH secretion in response to GHRH, which is indicative of neuroendocrine dysregulation, was observed in the Mafb cKO mice. However, it remains unknown how neuron-specific Mafb deletion results in the reduction of circulating IGF-I. Region- or cell-type-specific Cre drivers [10] would be helpful in solving this remaining issue.

$M A F B$ mutations in humans cause either multicentric carpotarsal osteolysis (MCTO [MIM 166300]) [24, 32] or a subset of Duane retraction syndrome (DRS [MIM 126800]) $[25,27]$ depending on the affected site. MCTO is characterized by childhood-onset arthritis, and DRS is characterized by congenital disorders of outward eye movement; both diseases are often accompanied by progressive nephropathy leading to end-stage renal disease. Unfortunately, neither postnatal skeletal growth nor blood concentrations of GH or IGF-I have been described in previous reports of these $M A F B$ mutation-mediated diseases. Our results may therefore be an important first look at hidden dysregulation in the GH/IGF-I axis within $M A F B$-mediated diseases.

In summary, our study using neuron-specific Mafb cKO mice revealed that MafB in neurons plays an important role for postnatal growth regulated by the $\mathrm{GH} /$ IGF-I axis.

\section{Acknowledgments}

We thank R. Kageyama (Kyoto University) for the generous gift of Nes-Cre mice and B. J. Mathis (University of Tsukuba) for English revision. This work was supported by a Grant-in-Aid for Scientific Research (16H06276A, S.T.) from the Ministry of Education, Culture, Sports, Science and Technology (MEXT) of Japan.

\section{References}

1. Baxter, R.C. 2014. IGF binding proteins in cancer: mechanistic and clinical insights. Nat. Rev. Cancer 14: 329-341.
[Medline] [CrossRef]

2. Blanchi, B., Kelly, L.M., Viemari, J.C., Lafon, I., Burnet, H., Bévengut, M., Tillmanns, S., Daniel, L., Graf, T., Hilaire, G. and Sieweke, M.H. 2003. MafB deficiency causes defective respiratory rhythmogenesis and fatal central apnea at birth. Nat. Neurosci. 6: 1091-1100. [Medline] [CrossRef]

3. Campbell, G.R.O., Baudhuin, A., Vranizan, K. and Ngai, J. 2011. Transcription factors expressed in olfactory bulb local progenitor cells revealed by genome-wide transcriptome profiling. Mol. Cell. Neurosci. 46: 548-561. [Medline] [CrossRef]

4. Cordes, S.P., and Barsh, G.S. 1994. The mouse segmentation gene $\mathrm{kr}$ encodes a novel basic domain-leucine zipper transcription factor. Cell 79: 1025-1034. [Medline] [CrossRef]

5. Eychène, A., Rocques, N. and Pouponnot, C. 2008. A new MAFia in cancer. Nat. Rev. Cancer 8: 683-693. [Medline] [CrossRef]

6. Fazeli, P.K., and Klibanski, A. 2014. Determinants of GH resistance in malnutrition. J. Endocrinol. 220: R57-R65. [Medline] [CrossRef]

7. Galichet, C., Lovell-Badge, R. and Rizzoti, K. 2010. NestinCre mice are affected by hypopituitarism, which is not due to significant activity of the transgene in the pituitary gland. PLoS One 5: e11443. [Medline] [CrossRef]

8. Hang, Y., and Stein, R. 2011. MafA and MafB activity in pancreatic $\beta$ cells. Trends Endocrinol. Metab. 22: 364-373. [Medline] [CrossRef]

9. Harno, E., Cottrell, E.C. and White, A. 2013. Metabolic pitfalls of CNS Cre-based technology. Cell Metab. 18: 21-28. [Medline] [CrossRef]

10. Harris, J.A., Hirokawa, K.E., Sorensen, S.A., Gu, H., Mills, M., Ng, L.L., Bohn, P., Mortrud, M., Ouellette, B., Kidney, J., Smith, K.A., Dang, C., Sunkin, S., Bernard, A., Oh, S.W., Madisen, L. and Zeng, H. 2014. Anatomical characterization of Cre driver mice for neural circuit mapping and manipulation. Front. Neural Circuits 8: 76. [Medline] [CrossRef]

11. Hasegawa, Y., Daitoku, Y., Sekiguchi, K., Tanimoto, Y., Mizuno-Iijima, S., Mizuno, S., Kajiwara, N., Ema, M., Miwa, Y., Mekada, K., Yoshiki, A., Takahashi, S., Sugiyama, F. and Yagami, K. 2013. Novel ROSA26 Cre-reporter knockin C57BL/6N mice exhibiting green emission before and red emission after Cre-mediated recombination. Exp. Anim. 62: 295-304. [Medline] [CrossRef]

12. Hawkes, C.P., and Grimberg, A. 2015. Insulin-Like Growth Factor-I is a Marker for the Nutritional State. Pediatr. Endocrinol. Rev. 13: 499-511. [Medline]

13. Isaka, F., Ishibashi, M., Taki, W., Hashimoto, N., Nakanishi, S. and Kageyama, R. 1999. Ectopic expression of the bHLH gene Math1 disturbs neural development. Eur. J. Neurosci. 11: 2582-2588. [Medline] [CrossRef]

14. Jin, Z., Liu, L., Bian, W., Chen, Y., Xu, G., Cheng, L. and Jing, N. 2009. Different transcription factors regulate nestin gene expression during P19 cell neural differentiation and central nervous system development. J. Biol. Chem. 284: 8160-8173. [Medline] [CrossRef]

15. Kamitani-Kawamoto, A., Hamada, M., Moriguchi, T., Miyai, M., Saji, F., Hatamura, I., Nishikawa, K., Takayanagi, H., Hitoshi, S., Ikenaka, K., Hosoya, T., Hotta, Y., Takahashi, 
S. and Kataoka, K. 2011. MafB interacts with Gcm2 and regulates parathyroid hormone expression and parathyroid development. J. Bone Miner. Res. 26: 2463-2472. [Medline] [CrossRef]

16. Katoh, M.C., Jung, Y., Ugboma, C.M., Shimbo, M., Kuno, A., Basha, W.A., Kudo, T., Oishi, H. and Takahashi, S. 2018. MafB Is Critical for Glucagon Production and Secretion in Mouse Pancreatic a Cells In Vivo. Mol. Cell. Biol. 38: e00504-17. [Medline] [CrossRef]

17. Liang, H., Hippenmeyer, S. and Ghashghaei, H.T. 2012. A Nestin-cre transgenic mouse is insufficient for recombination in early embryonic neural progenitors. Biol. Open 1: 1200-1203. [Medline] [CrossRef]

18. Liang, Q., Zhong, L., Zhang, J., Wang, Y., Bornstein, S.R., Triggle, C.R., Ding, H., Lam, K.S.L. and Xu, A. 2014. FGF21 maintains glucose homeostasis by mediating the cross talk between liver and brain during prolonged fasting. Diabetes 63: 4064-4075. [Medline] [CrossRef]

19. Lim, L., Pakan, J.M.P., Selten, M.M., Marques-Smith, A., Llorca, A., Bae, S.E., Rochefort, N.L. and Marín, O. 2018. Optimization of interneuron function by direct coupling of cell migration and axonal targeting. Nat. Neurosci. 21: 920931. [Medline] [CrossRef]

20. Milman, S., Huffman, D.M. and Barzilai, N. 2016. The Somatotropic Axis in Human Aging: Framework for the Current State of Knowledge and Future Research. Cell Metab. 23: 980-989. [Medline] [CrossRef]

21. Moriguchi, T., Hamada, M., Morito, N., Terunuma, T., Hasegawa, K., Zhang, C., Yokomizo, T., Esaki, R., Kuroda, E., Yoh, K., Kudo, T., Nagata, M., Greaves, D.R., Engel, J.D., Yamamoto, M. and Takahashi, S. 2006. MafB is essential for renal development and F4/80 expression in macrophages. Mol. Cell. Biol. 26: 5715-5727. [Medline] [CrossRef]

22. Morito, N., Yoh, K., Ojima, M., Okamura, M., Nakamura, M., Hamada, M., Shimohata, H., Moriguchi, T., Yamagata, K. and Takahashi, S. 2014. Overexpression of Mafb in podocytes protects against diabetic nephropathy. J. Am. Soc. Nephrol. 25: 2546-2557. [Medline] [CrossRef]

23. Morito, N., Yoh, K., Usui, T., Oishi, H., Ojima, M., Fujita, A., Koshida, R., Shawki, H.H., Hamada, M., Muratani, M., Yamagata, K. and Takahashi, S. 2018. Transcription factor MafB may play an important role in secondary hyperparathyroidism. Kidney Int. 93: 54-68. [Medline] [CrossRef]

24. Mumm, S., Huskey, M., Duan, S., Wenkert, D., Madson, K.L., Gottesman, G.S., Nenninger, A.R., Laxer, R.M., McAlister, W.H. and Whyte, M.P. 2014. Multicentric carpotarsal osteolysis syndrome is caused by only a few domain-specific mutations in MAFB, a negative regulator of RANKL-induced osteoclastogenesis. Am. J. Med. Genet. A.
164A: 2287-2293. [Medline] [CrossRef]

25. Park, J.G., Tischfield, M.A., Nugent, A.A., Cheng, L., Di Gioia, S.A., Chan, W.M., Maconachie, G., Bosley, T.M., Summers, C.G., Hunter, D.G., Robson, C.D., Gottlob, I. and Engle, E.C. 2016. Loss of MAFB Function in Humans and Mice Causes Duane Syndrome, Aberrant Extraocular Muscle Innervation, and Inner-Ear Defects. Am. J. Hum. Genet. 98: 1220-1227. [Medline] [CrossRef]

26. Perez, J.D., Rubinstein, N.D. and Dulac, C. 2016. New Perspectives on Genomic Imprinting, an Essential and Multifaceted Mode of Epigenetic Control in the Developing and Adult Brain. Annu. Rev. Neurosci. 39: 347-384. [Medline] [CrossRef]

27. Sato, Y., Tsukaguchi, H., Morita, H., Higasa, K., Tran, M.T.N., Hamada, M., Usui, T., Morito, N., Horita, S., Hayashi, T., Takagi, J., Yamaguchi, I., Nguyen, H.T., Harada, M., Inui, K., Maruta, Y., Inoue, Y., Koiwa, F., Sato, H., Matsuda, F., Ayabe, S., Mizuno, S., Sugiyama, F., Takahashi, S. and Yoshimura, A. 2018. A mutation in transcription factor MAFB causes Focal Segmental Glomerulosclerosis with Duane Retraction Syndrome. Kidney Int. 94: 396-407. [Medline] [CrossRef]

28. Shichita, T., Ito, M., Morita, R., Komai, K., Noguchi, Y., Ooboshi, H., Koshida, R., Takahashi, S., Kodama, T. and Yoshimura, A. 2017. MAFB prevents excess inflammation after ischemic stroke by accelerating clearance of damage signals through MSR1. Nat. Med. 23: 723-732. [Medline] [CrossRef]

29. Ueki, I., Ooi, G.T., Tremblay, M.L., Hurst, K.R., Bach, L.A. and Boisclair, Y.R. 2000. Inactivation of the acid labile subunit gene in mice results in mild retardation of postnatal growth despite profound disruptions in the circulating insulin-like growth factor system. Proc. Natl. Acad. Sci. USA 97: 6868-6873. [Medline] [CrossRef]

30. Wu, S., Yang, W. and De Luca, F. 2015. Insulin-like growth factor-independent effects of growth hormone on growth plate chondrogenesis and longitudinal bone growth. Endocrinology 156: 2541-2551. [Medline] [CrossRef]

31. Yakar, S., Werner, H. and Rosen, C.J. 2018. Insulin-like growth factors: actions on the skeleton. J. Mol. Endocrinol. 61: T115-T137. [Medline] [CrossRef]

32. Zankl, A., Duncan, E.L., Leo, P.J., Clark, G.R., Glazov, E.A., Addor, M.C., Herlin, T., Kim, C.A., Leheup, B.P., McGill, J., McTaggart, S., Mittas, S., Mitchell, A.L., Mortier, G.R., Robertson, S.P., Schroeder, M., Terhal, P. and Brown, M.A. 2012. Multicentric carpotarsal osteolysis is caused by mutations clustering in the amino-terminal transcriptional activation domain of MAFB. Am. J. Hum. Genet. 90: 494-501. [Medline] [CrossRef] 